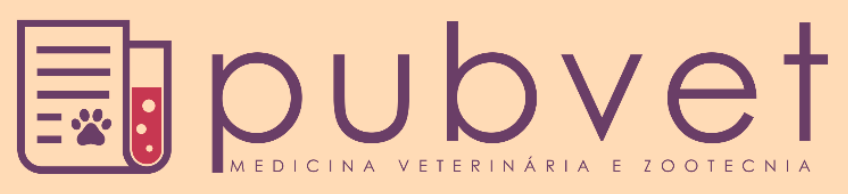

https://doi.org/10.31533/pubvet.v16n01a1016.1-5

\title{
Enfisema subcutâneo generalizado devido ferida perfurante axilar em equino: Relato de caso
}

\author{
Amanda Estefanir Cordeiro ${ }^{1}$, Gerôncio Sucupira Júnior ${ }^{2} \bullet$, Rodrigo Formiga Leite ${ }^{2}$, Luan \\ Aragão Rodrigues $^{1 *}$, Jorge Domingos da Silva Lima ${ }^{10}$ \\ ${ }^{I}$ Especialização em Medicina Veterinária, Instituto Federal da Paraíba - Campus Sousa, São Gonçalo, Sousa-PB, Brasil. \\ ${ }^{2}$ Médico Veterinário, Instituto Federal da Paraíba - Campus de Sousa, São Gonçalo, Sousa-PB, Brasil. \\ *Autor para correspondência, E-mail: luan.veterinaria@gmail.com
}

\begin{abstract}
Resumo. Enfisema subcutâneo é considerado como o acúmulo de gás no espaço subcutâneo e entre os feixes e fáscias musculares. O enfisema subcutâneo em equinos não é comum e pode ocorrer devido perfurações na traqueia ou em tecido cutâneo em regiões de intensa movimentação como resultado da sucção de ar para o espaço subcutâneo. Este relato consiste na descrição de uma égua da raça Quarto de milha, de cinco anos de idade, que sofreu um trauma perfurante na altura da região axilar decorrente de uma chifrada de um bovino. O animal foi atendido no Hospital Veterinário - Adílio Santos Azevedo (HVASA), do Instituto Federal da Paraíba - campus de Sousa, apresentando enfisema subcutâneo generalizado secundário a ferimento perfurante cuja melhora se deu com antibioticoterapia, terapia anti-inflamatória, limpeza diária da ferida e restrição da movimentação do animal. $\mathrm{O}$ animal recebeu alta após 21 dias. Observou-se assim que o enfisema generalizado secundário a feridas cutâneas pode apresentar um bom prognóstico, desde que diagnosticado e tratado corretamente.
\end{abstract}

Palavras-chave: Crepitação, gás, ferimento axilar

\section{Generalized subcutaneous emphysema secondary to perforating axillary wound in horse: Case report}

\begin{abstract}
Subcutaneous emphysema is considered as the accumulation of gas into the subcutaneous space and between the muscles bundles and fasciae. Subcutaneous emphysema in horses is rare and may be due to perforations of trachea and cutaneous tissue in regions of intense movement, resulting in air suction to the subcutaneous space. This report is a description of a 5-year-old Quarter Horse mare who suffered a perforating trauma at the axillary region due to the horning of a cattle. The animal was assisted at the Veterinary Hospital - Adílio Santos Azevedo (HV-ASA), from Instituto Federal da Paraíba - Campus Sousa, presenting generalized subcutaneous emphysema secondary to perforating wound which improved with antibiotic therapy, anti-inflamatory administration, daily wound cleaning and patient movement restriction. The animal discharged after 21 days. Thus, it was observed that secondary emphysema to skin wounds can have a good prognosis if treated correctly.
\end{abstract}

Keywords: Creptation, gas, axillary wound

\section{Introdução}

O enfisema é definido como o acúmulo de ar nos tecidos que pode provir de uma laceração na pele ou de alguma lesão na mucosa do trato respiratório. Esse ar é distribuído pelos tecidos pelas contrações musculares ou do movimento de estruturas em áreas adjacentes à lesão (Feldman, 1997; Larsson \& 
Lucas, 2016; Laskoski et al., 2015). Outras causas geralmente atribuídas ao enfisema são o acúmulo de gás devido proliferação bacteriana e perfurações em órgãos da respiração, como a traqueia e pulmão, ou ainda a traumas na cavidade torácica (Feldman, 1997; Larsson \& Lucas, 2016). Equinos são animais suscetíveis a lesões traumáticas devido ao seu comportamento ativo com manifestação de reações abruptas que aumentam o risco de choques mecânicos acidentais. Ambientes sujos e instalações inadequadas também elevam a chance de ocorrência de lesões assim como atividades esportivas e laborais (Paganela et al., 2009). O enfisema subcutâneo em equinos pode ocorrer após ferimentos perfurantes em locais de movimentação constante, como na região axilar (Feldman, 1997; Larsson \& Lucas, 2016; Laskoski et al., 2015).

O objetivo deste trabalho é relatar a ocorrência de um caso de enfisema subcutâneo generalizado em um equino, em virtude da ocorrência incomum desse tipo de problema nessa espécie e da escassez de relatos científicos sobre o tema.

\section{Relato de caso}

Um equino, fêmea, da raça Quarto de milha, cinco anos de idade e pesando $480 \mathrm{~kg}$ foi atendido no Hospital Veterinário Adílio Santos Azevedo (HV-ASA) do Instituto Federal da Paraíba (IFPB) campus de Sousa, com queixa de ferimento e inchaço por todo o corpo do animal.

O proprietário relatou que o equino havia sofrido uma chifrada na região axilar. Logo após o acidente, o animal foi atendido por um médico veterinário autônomo que realizou a limpeza do ferimento e a sutura de parte dos bordos da lesão. O profissional prescreveu limpeza da ferida operatória com água e sabão e posterior aplicação tópica de solução à base de permanganato de potássio. Instituiu ainda protocolo terapêutico parenteral antimicrobiano com Penicilina e terapia anti-inflamatória à base de dexametasona.

Após seis dias do início do tratamento, o quadro clínico se agravou com o surgimento do aumento de volume por todo o corpo do equino e o protocolo terapêutico foi modificado com o acréscimo de um medicamento à base de dexametasona associado ao triclorometiazida.

Não houve evolução clínica favorável e o animal foi encaminhado para o HV-ASA no oitavo dia após o acidente (Figura 1).

Durante o exame físico constatou-se aumento de volume na região axilar esquerda com ferimento lácero-perfurante de aproximadamente $12 \mathrm{~cm}$ de diâmetro, com deiscência de alguns pontos de sutura (Figura 2).

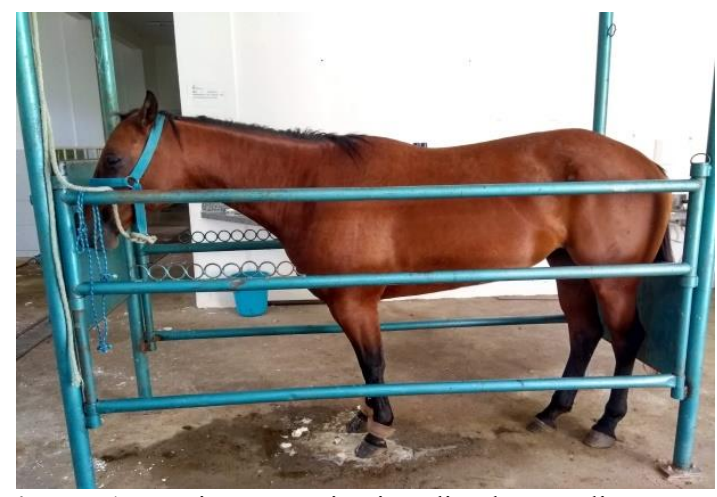

Figura 1. Equino no primeiro dia de atendimento no Hospital Veterinário A

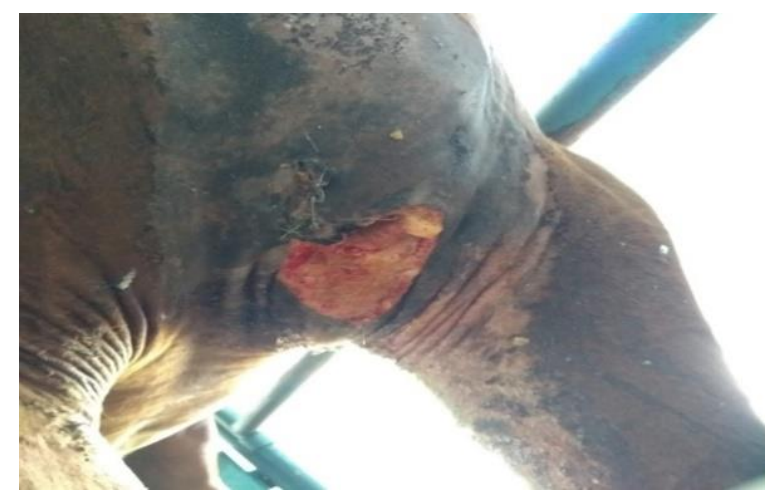

Figura 2. Ferimento lácero-perfurante na região axilar esquerda.

Adjacente à lesão havia crepitação subcutânea (Figura 3) que se estendia para as regiões ventral e laterais do pescoço, cabeça, regiões dorsal e ventral abdominal e, ainda, parte da garupa.

Não havia enfisema nas regiões distais dos quatro membros e o animal não demonstrou desconforto à palpação das áreas enfisematosas. 
Os parâmetros fisiológicos do exame físico geral estavam dentro dos valores de referência para a espécie, embora houvesse certa dificuldade na auscultação devido ao abafamento dos ruídos provocado pelo enfisema distribuído no espaço subcutâneo. $\mathrm{O}$ hemograma não revelou alteração.

Foi coletada amostra do exsudato do ferimento para avaliação microbiológica a qual resultou negativa para a presença de bactérias do gênero Clostridium $\mathrm{sp}$.

Foi instaurada antibioticoterapia profilática com medicamento à base de Benzilpenicilina (Pencivet Plus PPU(C), via intramuscular, na dosagem de $44.000 \mathrm{UI} / \mathrm{kg}$, a cada 48 horas, perfazendo quatro aplicações; e Sulfato de Gentamicina $\left(\right.$ Gentamax $^{\mathcal{O}}$ ) via subcutânea, na dosagem de 3,7 mg/kg, uma vez ao dia durante sete dias. A terapia anti-inflamatória foi instaurada à base de Fenilbutazona (Equipalazone $^{\odot}$ ) na dosagem de $3 \mathrm{mg} / \mathrm{kg}$, via endovenosa, uma vez ao dia durante três dias. Foi feita a administração de uma ampola de soro anti-tetânico (Vencosat ${ }^{\circ}$ ), a qual foi repetida após 15 dias.

Duchas frias foram aplicadas sobre as áreas enfisematosas e sobre o ferimento antes da limpeza. O tratamento da ferida consistiu na higienização, duas vezes ao dia, da lesão axilar com solução de cloreto de sódio a $0,9 \%$ e clorexidine degermante a $2 \%$, seguido da aplicação tópica de spray à base de antimicrobiano e anti-inflamatório $\left(\right.$ Terracam $\left.^{\odot}\right)$.

No segundo dia de internamento foi realizada a drenagem do conteúdo enfisematoso subcutâneo (Figura 4) nas áreas de maior concentração gasosa na altura do músculo masseter e tríceps braquial, seguida de massagem do sentido distal para o centro da incisão cutânea.

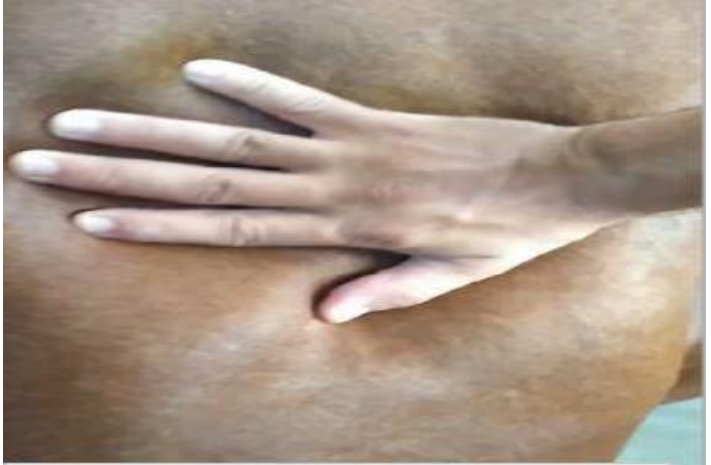

Figura 3. Área com acúmulo de gás subcutâneo.

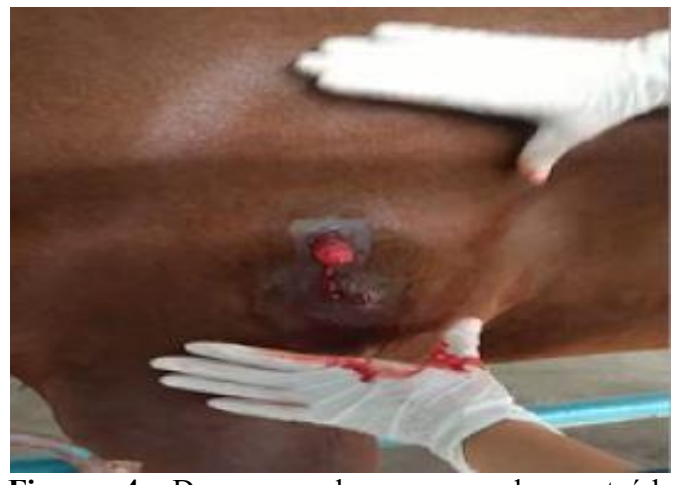

Figura 4. Drenagem do excesso de conteúdo enfisematoso subcutâneo.

A paciente foi mantida em baia com o intuito de restringir sua movimentação (Figura 5).

O protocolo clínico promoveu regressão progressiva do enfisema generalizado a partir do quarto dia de tratamento até a redução completa no décimo dia de intervenção. A ferida na região axilar cicatrizou após 21 dias de internação (Figura 6).

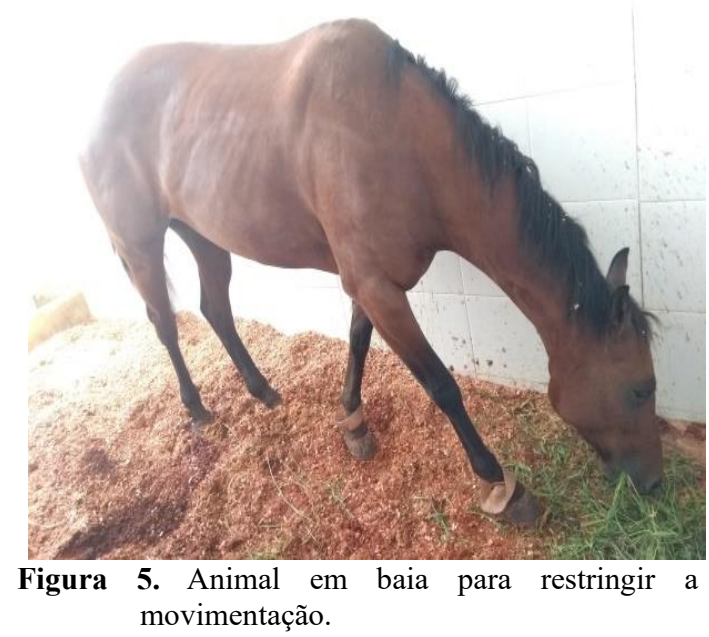

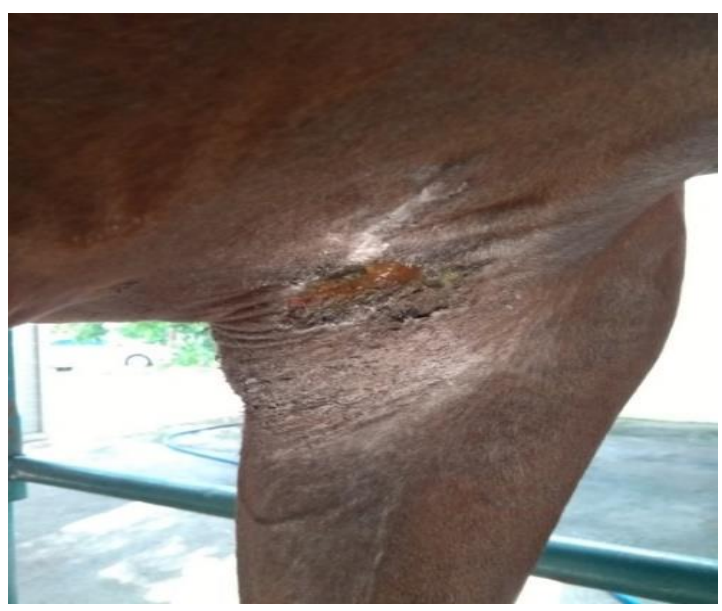

Figura 6. Cicatrização do ferimento na região axilar esquerda. 


\section{Discussão}

O enfisema subcutâneo é considerado incomum em equinos e a negligência na instituição de um tratamento rápido e correto pode ocasionar em complicações, inclusive o óbito (Bonacin et al., 2018). Feridas perfurantes em locais de intensa movimentação geralmente determinam a formação de enfisema subcutâneo devido à sucção de ar para o espaço subcutâneo. Perfurações traqueais também podem ocasionar o surgimento de enfisema (Feldman, 1997; Larsson \& Lucas, 2016; Laskoski et al., 2015; Thomassian, 2005).

Em casos onde há o envolvimento de exotoxinas oriundas de afecções clostrídicas pode-se observar alterações na série eritrocitária, por processo hemolítico, que é causada pela mesma toxina que produz mionecrose e gangrena gasosa em animais. Anemia imunomediada já foi constatada em equinos com enfisema secundário à infecção por Clostridium perfringens (Weiss \& Moritz, 2008).

Complicações graves consistem na ocorrência de pneumotórax, pneumomediastino ou outras alterações pulmonares que podem resultar em cianose, embora casos de pneumotórax estejam mais associados a trauma torácico aberto ou fechado (Boy \& Sweeney, 2000). O exame clínico meticuloso é imprescindível para o estabelecimento do diagnóstico e para uma orientação terapêutica adequada (Feitosa, 2014).

A desfiguração cosmética temporária é a característica principal da afecção. No entanto, outras complicações mais sérias podem ocorrer dependendo da região afetada como, por exemplo, aumento da pressão intracraniana, obstrução das vias aéreas superiores devido ao enfisema retrofaringeano, cegueira causada por dano ao nervo óptico resultante de enfisema orbital e disfunções cardiopulmonares pelo aumento da concentração de dióxido de carbono no sangue arterial provocados pela inibição dos movimentos da parede torácica (Larsson \& Lucas, 2016; Laskoski et al., 2015).

A terapia com antimicrobianos deve ser conduzida com cuidado, selecionando-se drogas efetivas no controle da infecção, ou no uso profilático, e respeitando-se as dosagens e esquemas posológicos apropriados (Andrade, 2011). Na hipiatria, esquemas antimicrobianos à base de betalactâmicos, aminoglicosídeos e nitroimidazólicos são comumente empregados (Andrade, 2011).

Terapia anti-inflamatória à base de corticoide é contraindicada em casos de ferimentos perfurantes devido à inibição da síntese do colágeno necessário à cicatrização. Uso de anti-inflamatórios nãoesteroidais são considerados a melhor opção para o tratamento dessas afecções (Melo et al., 2009).

A profilaxia antitetânica é fundamental em casos de animais acometidos por ferimentos contaminados em virtude do tétano ser uma doença infecciosa extremamente fatal e as lesões cutâneas serem consideradas a porta de entrada para a contaminação e disseminação da infecção (Thomassian, 2005).

A restrição da movimentação do animal é considerada uma medida fundamental no tratamento de animais com enfisema subcutâneo secundário à ferimento em virtude do impedimento da sucção de ar ocasionada pela ambulação (Bonacin et al., 2018).

Várias técnicas têm sido utilizadas para tratar o enfisema subcutâneo, muitas das quais invasivas ou desconfortáveis que poderiam agravar o quadro como a colocação de drenos torácicos adicionais intrapleurais ou subcutâneos (Thomassian, 2005).

O prognóstico para o enfisema subcutâneo em decorrência de ferimento é considerado bom (Bonacin et al., 2018).

\section{Conclusão}

A ocorrência de enfisema subcutâneo generalizado em equino é rara na rotina clínica e passível de complicações, mas o prognóstico é favorável. O exame clínico deve ser realizado de forma acurada para que a terapia seja estabelecida o mais rápido possível evitando-se complicações ou agravamento do quadro clínico.

\section{Referências bibliográficas}

Andrade, S. F. (2011). Manual de terapêutica veterinária. Editora Roca. 
Bonacin, Y. S., Sousa, S. S., Bueno, G. M., Chítero, A., Marques, J. A., \& Canola, P. A. (2018). Enfisema subcutâneo generalizado, decorrente de ferida perfurante em equino. Revista Acadêmica Ciência Animal, 16(1), 1-5. https://doi.org/10.7213/1981-4178.2018.162503.

Boy, M. G., \& Sweeney, C. R. (2000). Pneumothorax in horses: 40 cases (1980-1997). Journal of the American Veterinary Medical Association, 216(12), 1955-1959.

Feitosa, F. L. F. (2014). Semiologia veterinária: A arte do diagnóstico. Grupo Gen-Editora Roca Ltda.

Feldman, E. C. (1997). Tratado de medicina interna veterinária. In Moléstias do cão e do gato (Vol. 3).

Larsson, C. E., \& Lucas, R. (2016). Tratado de medicina externa: dermatologia veterinária. Interbook.

Laskoski, L. M., Fioravanti, R. A. B., Doria, R. G. S., Carvalho, M. B., \& de Freitas, S. H. (2015). Enfisema subcutâneo generalizado em um equino após ferida axilar-Relato de caso. Brazilian Journal of Veterinary Medicine, 37(1), 93-96.

Melo, U. P., Fiório, R. C., Araújo, T. B. S., \& Ferreira, C. (2009). Intoxicação por fenilbutazona em equino: relato de caso. Acta Veterinaria Brasilica, 3(2), 111-116. https://doi.org/10.21708/avb.2009.3.2.1265.

Paganela, J. C., Ribas, L. M., Santos, C. A., Feijó, L. S., Nogueira, C. E. W., \& Fernandes, C. G. (2009). Abordagem clínica de feridas cutâneas em equinos Clinical approach in equine skin wounds. Ciências Veterinárias, 104, 13-18.

Thomassian, A. (2005). Enfermidades dos cavalos. Livraria Varela.

Weiss, D. J., \& Moritz, A. (2008). Equine imunomediated hemolytic anemia associated with Clostridium perfringens infection. Veterinary Clinical Pathology, 32, 22-26.

Histórico do artigo:

Recebido: 14 de outubro de 2021

Aprovado: 12 de novembro de 2021

Disponível online: 31 de dezembro de 2021
Licenciamento: Este artigo é publicado na modalidade Acesso Aberto sob a licença Creative Commons Atribuição 4.0 (CC-BY 4.0), a qual permite uso irrestrito, distribuição, reprodução em qualquer meio, desde que o autor e a fonte sejam devidamente creditados. 